\title{
Mathematical model of heat supply of rooms for Automated control systems of energy saving
}

\author{
Sedov Artem ${ }^{1, a}$, Ainagulova Aliya ${ }^{2, b}$ and Temirgaliyeva Ainur ${ }^{3, c}$ \\ ${ }^{1}$ Moscow State University of Civil Engineering, Moscow, Russia \\ ${ }^{2}$ L.N.Gumilev Eurasian National University, Astana, Kazakhstan \\ ${ }^{3}$ L.N.Gumilev Eurasian National University, Astana, Kazakhstan \\ asedov.eit@gmail.com, baliya080982@mail.ru, cainur.temirgaliyeva@mail.ru
}

Keywords: heat supply of rooms, system of the nonlinear differential equations, computer model, thermal energy, experiment.

Abstract. On the basis of the nonlinear differential equations systems was developed and realized in a Math Lab package the behavior model of thermal processes indoors for automated control system of energy saving.

The received results give the chance to carry out monitoring of a thermal state rooms.

The constructed mathematical model can form a basis for creation of algorithm and software of ACS heat supply as certain rooms, and whole buildings and constructions.

One of the most actual problems in the field of life support systems of buildings is energy saving. Monitoring of problems of this problem shows that the most important link in its decision is rational use of thermal energy, especially on areas of "end users".

The purpose of this work is creation of mathematical model for a quality assessment uses of thermal energy on the example of heat supply of randomly chosen rooms.

In any control system of heating the task optimum on expenses is set managements of temperature indoors, creation of the comfortable conditions corresponding to purpose of rooms. Maintenance of comfortable and/or safe temperature in each time point is the purpose of creation automatic control systems. Remote control of heating depending on numerous internal and external conditions allows to achieve considerable economy of energy resources with other things being equal.

For the solution of an objective it is necessary to formulate prerequisites which are the basis for reasonings:

1. Regulation of temperature of the heat carrier for measurement of air temperature in the room.

2. Maintenance of the set temperature condition, despite change of the external conditions.

3. Regulation of temperature in power effective systems of heating is made taking into account the following external conditions: environment air temperature, time of day, day of the week, season (winter, summer).

\section{Mathematical model of heat supply of rooms}

The mathematical description of thermal processes in buildings and rooms, as a rule, it is realized in the stationary mode when thermal streams and parameters of a thermal contour are constant, don't depend on time. So parameters of thermal processes are set in a help view [1]. These are such parameters as a thermal capacity of walls and overlappings, coefficients of a heat transfer of the protecting designs, thermolysis coefficients heating devices, interrelation of characteristics with temperature of external air and adjacent rooms [2].

The stationary mode is understood as a situation indoors when it is observed balance between the arriving thermal energy and given by the room to the external area. Generally the stationary mode is one of possible situations. Any heat exchange has dynamic character, and for its description of one stationary mode isn't enough [3]. 
The method of the differential balance equations is the basis for mathematical modeling [4]. As dependent variables for drawing up balance the thermal energy brought to object and disseminated in environment is used.

Let consider as an example the model of the room which is limited to the internal walls and overlappings making a contour, an external wall with a window and heat sources. Increment of thermal energy occurs at the expense of heating devices, and its decrease due to absorption of walls, heat exchange with adjacent rooms (a corridor, a ladder, the platform), emissions in environment through a window and an external wall. In addition it is necessary to consider transfer of air masses due to unorganized ventilation, cracks in window frames and doors (a so-called infiltration).

Let write down the equation of change of thermal energy of the $Q_{1}$ air mass concluded in the room of $V$ :

$$
\frac{d Q_{1}}{d t}=R_{i s t} \cdot\left(T_{i s t}-T_{1}\right)-C_{k} \cdot\left(T_{1}-T_{2}\right)-R_{\text {vnesh }} \cdot\left(T_{1}-T_{\text {vnesh }}\right)
$$

where $R_{i s t}$ - resistance of the emission (heat transfer) of the heat carrier; $R_{\text {vnesh }}-$ emission resistance in environment; $C_{k}-$ a contour thermal capacity; $T_{i s t}-$ temperature of the heat carrier $\left({ }^{\circ} \mathrm{C}\right)$; $T_{1}$ - air temperature in $\left({ }^{\circ} \mathrm{C}\right) ; T_{2}$ - temperature of a contour $\left({ }^{\circ} \mathrm{C}\right)$; Tvnesh - environment temperature.

Let write down the similar equation for system of a contour into which walls enter and overlappings, adjacent rooms and system of heating devices (struts and batteries).

$$
\frac{d Q_{2}}{d t}=C_{k} \cdot\left(T_{1}-T_{2}\right)-R_{s m} \cdot\left(T_{2}-T_{s m}\right)
$$

where $C_{k}$ - a contour thermal capacity; $R_{s m}$ - emission resistance to the neighboring room; $T_{s m}-$ the air temperature of the adjacent room $\left({ }^{\circ} \mathrm{C}\right)$.

Here it is necessary to notice that the coefficients entering the equations have integrated character and can be found experimentally.

For further consideration we will introduce some simplifications. Let suppose that temperature of adjacent rooms coincides with temperature of our room, and temperatures of the heat carrier and environment don't depend on time. In this case system the equations it is move to system from two equations.

Introduce ratios:

$$
\begin{aligned}
& Q_{1}=C_{1} \cdot T_{1} \cdot V_{1}, \\
& Q_{2}=C_{2} \cdot T_{2} \cdot V_{2},
\end{aligned}
$$

where $C_{1}-$ specific heat of air; $C_{2}-$ specific heat of a contour; $V_{1}-$ room volume; $V_{2}-$ contour volume.

Taking into account ratios (3) and (4) we will receive the following system of the equations describing behavior of temperatures:

$$
\left\{\begin{array}{l}
\frac{d T_{1}}{d t}=\frac{R_{i s t} \cdot\left(T_{i s t}-T_{1}\right)}{C_{1} V_{1}}-\frac{C_{k} \cdot\left(T_{1}-T_{2}\right)}{C_{1} V_{1}}-\frac{R_{v n e s h} \cdot\left(T_{1}-T_{\text {vnesh }}\right)}{C_{1} V_{1}} \\
\frac{d T_{2}}{d t}=\frac{C_{k} \cdot\left(T_{1}-T_{2}\right)}{C_{2} V_{2}}
\end{array}\right.
$$


Such view is more preferable from the point of view of modeling of temperature condition in our environment and from the point of view of interpretation of results of experiment. It is necessary to consider that these equations have to be added with entry conditions. For example, by means of a task of air temperature and temperature of a contour in the initial time point.

\section{Experiment}

For obtaining temperature dependence of the room and finding of parameters contour experiment was made. The essence of experiment consisted in the following.

Temperature sensors were placed on walls and overlappings in several places with that it was possible to receive then the average integrated coefficient connected with a thermal capacity of walls and overlappings. At the same time sensors were placed in air, on the heat carrier and in environment. Temperature data were taken off through an interval one minute, and these data could be averaged on those sets about which it was told earlier.

Air and walls of the room were cooled due to inflow of cold air from environment. Thus at the expense of a contour lag effect cooling of walls was less, than air cooling. Then the system of the room was given to natural state, and there was a heating of volume of air and walls due to inflow of heat from the heating sources. This process of heating was fixed by means of described system of temperature sensors.

The received experimental dependences are given in picture 1 .

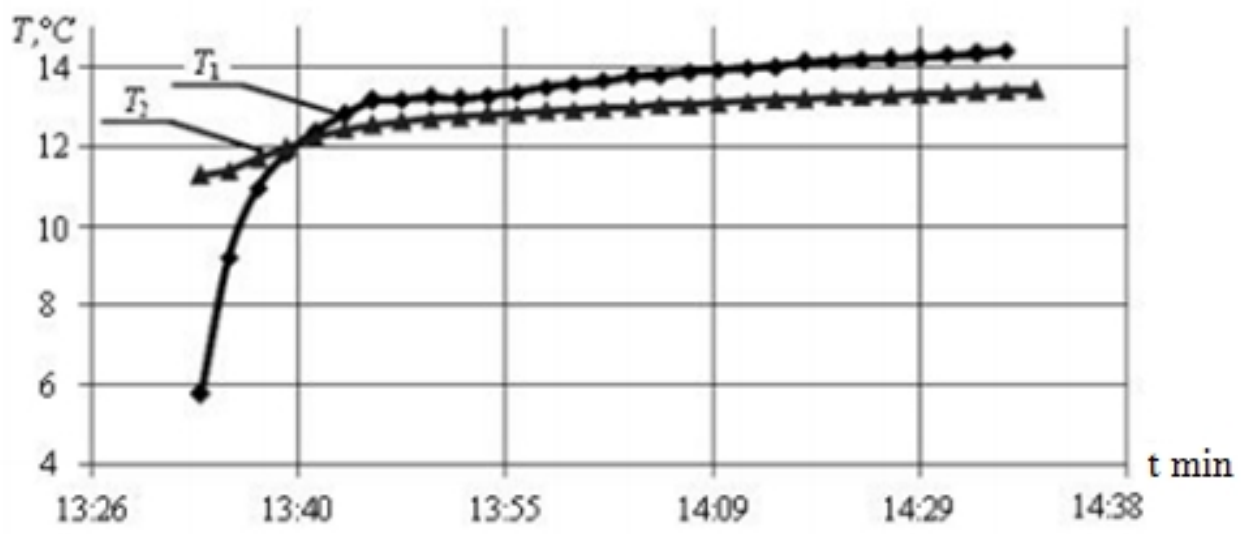

Fig. 1. Experimental dependences of air temperature of $T_{1}$ and temperature of a contour of $T_{2}$ on time

From picture 1 it is visible that reference temperatures for air and walls are various, speed of increasing temperature for air exceeds the speed of increasing temperature for contour, but over time they strive for the same stationary value. Besides, from picture 1 it is visible that crossing of two curves in some point takes place. The received experimental curves were used for finding of the parameters $R_{i s t}, R_{\text {vnesh }}, C_{k}$.

Values of the received parameters were compared to those help data [2], which are to us were known. These data are provided in the table.

Comparison of experimentally obtained and help data

\begin{tabular}{|c|c|c|}
\hline Characteristic & Experiment & Help data \\
\hline$R_{i s t},{ }^{\circ} C \cdot M^{2} / B m$ & $\mathbf{2 , 6}$ & $\mathbf{1 , 6 5}$ \\
\hline$R_{\text {vnesh }},{ }^{\circ} C \cdot M^{2} / B m$ & $\mathbf{3 , 2}$ & $\mathbf{1 , 9}$ \\
\hline$C_{k},{ }^{\circ} C \cdot M^{2} / B m$ & $\mathbf{3 0 , 8}$ & $\mathbf{2 6 , 4}$ \\
\hline
\end{tabular}


From comparison it is visible that there is coincidence in the order of size, but there are also divergences. These divergences can be explained to the following. Real values of materials of walls, real values of a condition of heating system, i.e. the battery, can significantly to differ in comparison with help data. The experimental values received by us have to be more exact and more concrete for each case.

\section{Modelling}

The found values of parameters together with system of the equations (5) allowed to carry out further modeling and the analysis of the thermal modes of the room. For this purpose we changed values of temperature of the battery. The following cases were analyzed.

Reference temperatures of walls and air were various. And air temperature rooms there was less than temperature of a contour.

This case is given in picture 2 .
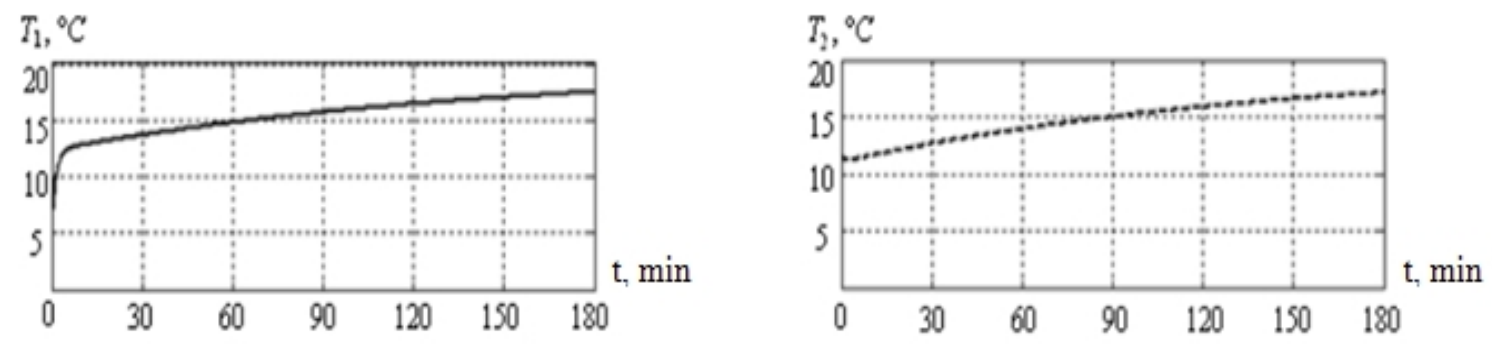

Fig. 2. Dependences of air temperature of $T_{1}$ and $T_{2}$ contour temperatures from time

The analysis of the dependences received by modeling and comparison them with experimental dependences showed good coincidence. Divergence error results makes no more than $5 \%$.

The second case - reference temperatures of a contour and air are identical. Received curves for different values of reference temperatures are given in picture 3 .

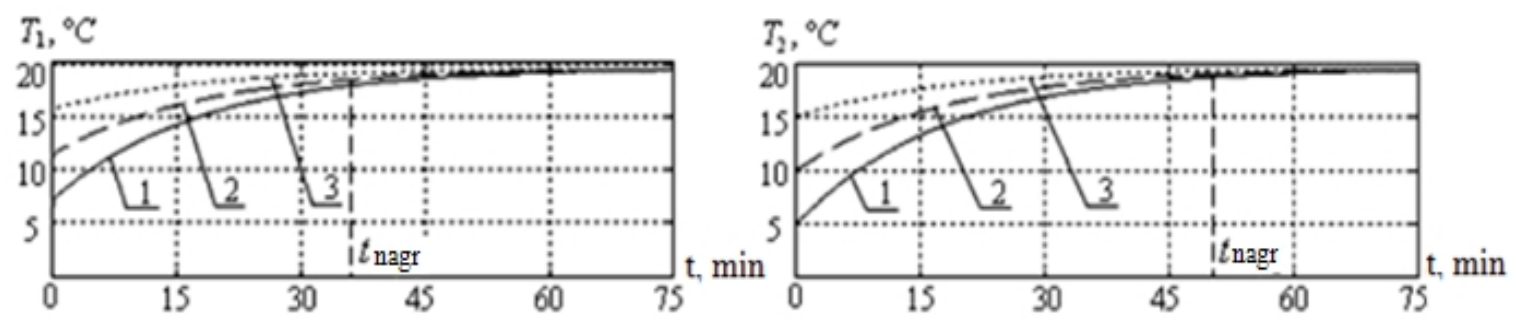

Fig.3. Dependences of air temperature of $T_{1}$ and $T_{2}$ contour temperatures from time at change of entry conditions: $1-T_{\text {nach }}=5{ }^{\circ} \mathrm{C}, 2-T_{\text {nach }}=10^{\circ} \mathrm{C}, 3-T_{\text {nach }}=15^{\circ} \mathrm{C}$

In picture 3 dependences of exponential character with a phase of the fast are represented increase of air temperature and slower increase of temperature of a contour. Both dependences come to the stationary mode after a while. This time transition process in itself is very important characteristic, as allows to consider a lag effect of heating or cooling of the room [5].

Let introduce concept of the "heating time" parameter. We will understand as this time interval of time during which temperature changes as follows: $0,99 \cdot\left(T_{\text {staz }}-T_{o}\right)+T_{o}$. In our case time of heating of air of the room makes $36 \mathrm{~min}$., for a contour $-50 \mathrm{~min}$. at the reference temperatures of a contour and air of $10^{\circ} \mathrm{C}$. 
Research of processes of cooling was the following stage of modeling. In this case in a steady state of air temperature and a contour had the maximum value. Value of temperature of the battery, thus other parameters changed remained constants. As a result temperature of the room fell, i.e. occurred cooling. Characteristic dependences are given in picture 4 [6].
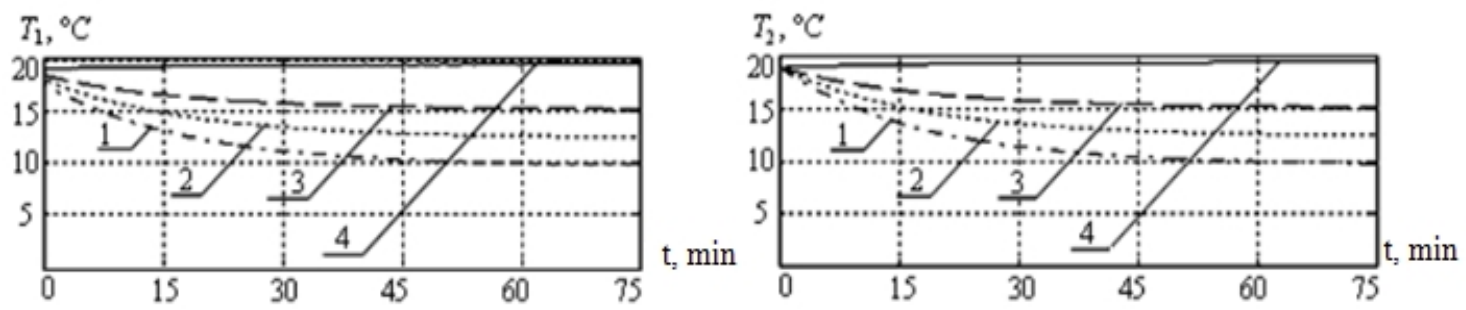

Fig.4. Dependences of air temperature of $T_{1}$ and $T_{2}$ contour temperatures from time when cooling: $1-T_{\text {ist }}=30{ }^{\circ} \mathrm{C}, 2-T_{\text {ist }}=35^{\circ} \mathrm{C}, 3-T_{\text {ist }}=40^{\circ} \mathrm{C}, 4-T_{i s t}=48{ }^{\circ} \mathrm{C}$

In picture 4 it is possible to observe various behavior of curves for air of the room and contour, but these dependences have identical exponential character. Speed cooling will be various. Here too it is possible to enter concept of time of cooling which is defined as follows: $T_{o}-0,99 \cdot\left(T_{o}-T_{\text {staz }}\right)$. In our experiment the received time of cooling makes for air $-34 \mathrm{~min}$., for a contour $-45 \mathrm{~min}$. at value of temperature of the battery of $30^{\circ} \mathrm{C}$.

The received results can be used both for monitoring, and for automated management of a thermal condition of the room. As an example we will consider a case when temperature condition at the enterprise has two phases (picture 5):

The 1st working phase - working hours from $8 \mathrm{~h}$ morning to $8 \mathrm{~h}$ evening;

The 2 nd phase of expectation - it corresponds the temperature of expectation, and this phase extends on other $12 \mathrm{~h}$ days.

During the first phase the model of heating of the room, when works for us after waiting mode the system heats up in the beginning, and then passes into a working condition. If the system joins in 7 $\mathrm{h}$ morning, during heating of $\mathrm{t}=36 \mathrm{~min}$. it moves on steady state. During the working day she is supported in a steady state and somewhere in $19.00 \mathrm{~h}$ passes into a state, when battery temperature significantly decreases, and during time of cooling of $\mathrm{t}=34 \mathrm{~min}$. it passes into other steady state when temperature becomes indoors much lower.
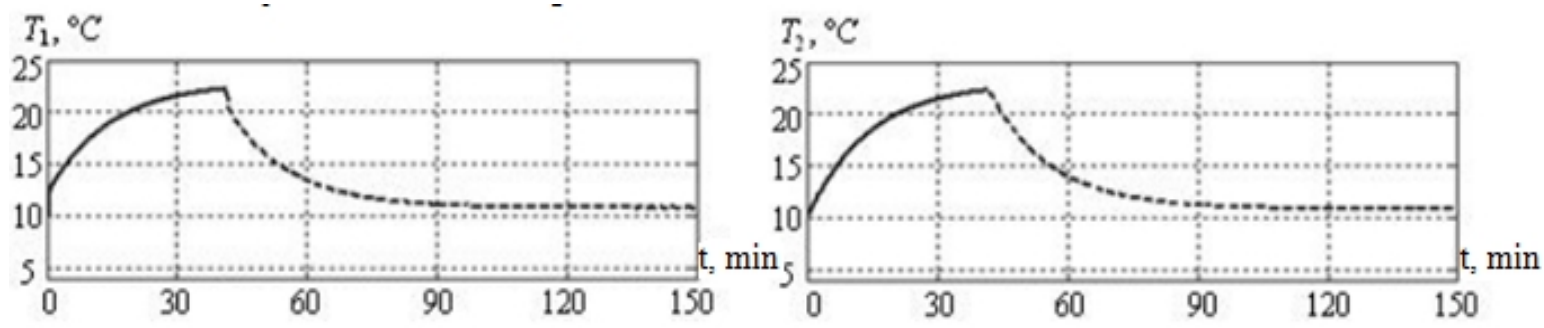

Fig.5. Two phases of temperature condition for temperatures of $T_{1}$ air and $T_{2}$ contour

Let estimate economy which turns out at introduction of the 2-phase mode of heat supply. In the beginning we will calculate thermal energy which is consumed by the room within a day without switching on an expectation phase:

$$
Q_{1}=\int_{0}^{24} R_{i s t} \cdot\left(T_{i s t}-T_{1}\right) d t=\int_{0}^{24} 2,6 \cdot(53-22) d t=1934,4 \kappa \kappa a л / c
$$

Then we will count the thermal energy consumed by the room in that case when during the first phase the heating mode (the first steady state) works, and then during other $12 \mathrm{~h}$ the second phase works. Thus working temperature we will consider $22^{\circ} \mathrm{C}$, expectation temperature $-11^{\circ} \mathrm{C}$. 


$$
Q_{2}=\int_{0}^{12} R_{i s t} \cdot\left(T_{i s t}-T_{1}\right) d t+\int_{12}^{24} R_{i s t} \cdot\left(T_{i s t}-T_{1}\right) d t=\int_{0}^{12} 2,6 \cdot(53-22) d t+\int_{12}^{24} 26 \cdot(32-1 \mathrm{D}) d t=744+6552=139,2 \kappa \kappa a d c
$$

The economy reaches $27 \%$.

\section{References}

[1]Heo Y., Choudhaiy R.. Augenbroe G.A. 2012. Calibration of building energy models for retrofit analysis under imcertainty. Energy and Buildings, vol. 47, pp. 550-560.

[2]Kennedy M.C.. O'Hagan A. 2001. Bayesian calibration of computer models. Journal of Royal Statistical Society B. vol. 63, pp.425-464.

[3]Macdonald. I. 2009. Comparison of sampling techniques on the performance of Monte-Carlo based sensitivity analysis. In 11th International IBPSA Conference, pp. 992-999, Glasgow.

[4]Matsuoka, A. Yamaguchi, Y. Suzuki, Y., Shimoda. Y. 2013. Urban-scale Modeling of Energy Demand of Retail Facilities. The Proceedings of the Building Simulation 2013.

[5]Suzuki. Y. Yamaguchi. Y. Shiraishi. K. Narumi, D. Shimoda. Y. 2011. Analysis and modeling of energy demand of retail stores. The Proceedings of the Building Simulation 2011, pp. 1824-1831.

[6]Yamaguchi Y.. Shimoda Y. 2010. District-scale Simulation for Multi-purpose Evaluation of Urban Energy Systems. Journal of Building Performance Simulation, vol. 3. pp. 289-305.

[7]Yamaguchi Y. et al. 2012. Classification of Japanese Retail Facilities to Establish Benchmark Energy Consumption, Proceedings of ACEEE Summer Study 2012. San Francisco. 